PAPER

\title{
Isolated monoparesis following stroke
}

\author{
M Paciaroni, V Caso, P Milia, M Venti, G Silvestrelli, F Palmerini, K Nardi, S Micheli, G Agnelli
}

J Neurol Neurosurg Psychiatry 2005;76:805-807. doi: 10.1136/jnnp.2004.047779

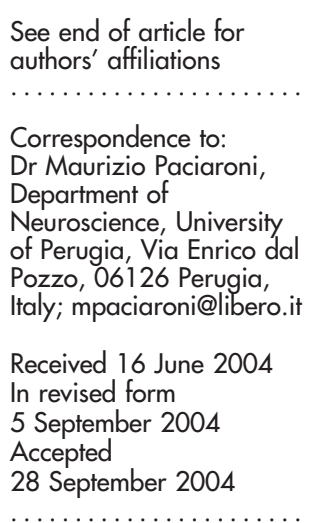

\begin{abstract}
Background: Some investigators have stated that monoparesis is almost never the result of a lacunar infarct or cerebral haemorrhage.

Objective: To describe the topography and aetiology in a consecutive population where first ever stroke was manifested by isolated monoparesis.

Methods: Patients with motor paresis of only one limb were included consecutively in the study. A neuroradiologist determined stroke location, while a neurologist reviewed the clinical records to assign stroke subtype. Both physicians worked blind to each other's findings.

Results: 51 of 2003 patients (2.5\%) had isolated monoparesis, and of these $39(76.5 \%)$ were ischaemic strokes and $12(23.5 \%)$ were haemorrhagic. Cardioembolism was the cause of stroke in $15.7 \%$, atherosclerosis in $9.8 \%$, and small artery disease in $39.2 \%$. Most of the haemorrhages were in the thalamic-capsular region (5/12). Most of the ischaemic lesions were in the deep territory of the middle cerebral artery, the corona radiate, or the centrum semiovale (20/39); 16 of 39 were in the cortical territories or the watershed region.

Conclusions: Isolated monoparesis is a rare symptom in stroke patients and is often caused by small artery disease or a small haemorrhage.
\end{abstract}

S ome investigators have stated that isolated monoparesis is almost never caused by a lacunar infarct or a cerebral haemorrhage, ${ }^{1-3}$ and that the lesion is usually localised in the cortex or centrum semiovale. However, in previous studies in patients with monoparesis caused by stroke, cerebral computed tomography (CT) showed no lesions in about $40 \%$ of the patients. These findings may reflect the fact that some small infarcts are not revealed by CT. ${ }^{14}$ Recent advances in neuroimaging using magnetic resonance imaging (MRI) and new generation CT could enable the identification of small vascular lesions causing monoparesis. ${ }^{5}$

In this study, we describe the stroke type, topography, and aetiology in 51 patients in whom first ever stroke was manifested by isolated monoparesis.

\section{METHODS}

We studied all consecutive patients included prospectively between January 1998 and August 2003 with paresis of only one limb and without any sensory disturbances. The following criteria were required:

- the presence of isolated motor deficit in either a leg or an arm without sensory disturbance, coordination deficit, or language deficit, and no significant involvement of speech or the ipsilateral face;

- the motor deficit was caused by an ischaemic or haemorrhagic stroke confirmed both clinically and radiologically.

We also included patients with minor signs on neurological examination such as pronation drift but with a subjective sudden reduction in strength described by the patients and persisting for more than 24 hours.

Every patient underwent brain CT without contrast in the acute phase, and this was repeated three to seven days from stroke onset. In addition, all the patients had an electrocardiogram, ultrasound examination of the supra-aortic vessels, and a transthoracic echocardiogram. Selected patients underwent cerebral MRI (for example, patients with negative CT), magnetic resonance angiography, cerebral angiography, and transoesophageal echocardiography. The lesion (infarct or haemorrhage) and the vascular territory were localised by CT and MRI according to previously reported criteria. ${ }^{67}$ Patients were studied for vascular risk factors.

A neuroradiologist determined stroke location, blinded to the clinical subtype of stroke, while a neurologist reviewed the medical records of each patient and assigned stroke subtype on the basis of the TOAST ("trial of ORG 10172 in acute stroke treatment") criteria. $^{8}$

Associations among anatomical location of the lesion, aetiological subtype of stroke (ischaemic or haemorrhagic), and deficit distribution (upper or lower limb) were assessed using the $\chi^{2}$ test or Fisher's exact test with Yates's correction when appropriate.

\section{RESULTS}

Fifty one of 2003 patients (2.5\%; mean (SD) age, 71.5 (12.5) years; $51 \%$ male) had paresis of only one limb without any sensory disturbance or other symptoms: 39 (76.5\%) were ischaemic strokes (fig 1) and 12 (23.5\%) were haemorrhagic (fig 2). The lesion was evident on CT in 29 patients and on MRI in the other 22. Thirty four patients had a monoparesis involving an upper limb and 17 a lower limb. The patients' characteristics are listed in table 1 . All the haemorrhages were of less than $2 \mathrm{~cm}$ diameter. The majority of haemorrhages were in the thalamic-capsular region (5/13). Cardioembolism was the cause of stroke in eight patients $(15.7 \%)$, atherosclerosis in five $(9.8 \%)$, and small artery disease in 20 (39.2\%). The cause remained undetermined in nine patients (17.6\%), while hypertensive arteriopathy was the cause in the remaining nine $(17.6 \%)$, and was seen only in patients with haemorrhagic stroke. The vascular territories and aetiological subtype are given in table 2 .

Four patients had slight dizziness and nine had slight dysarthria. All these symptoms were present during the initial phase of the stroke and were reversible. 

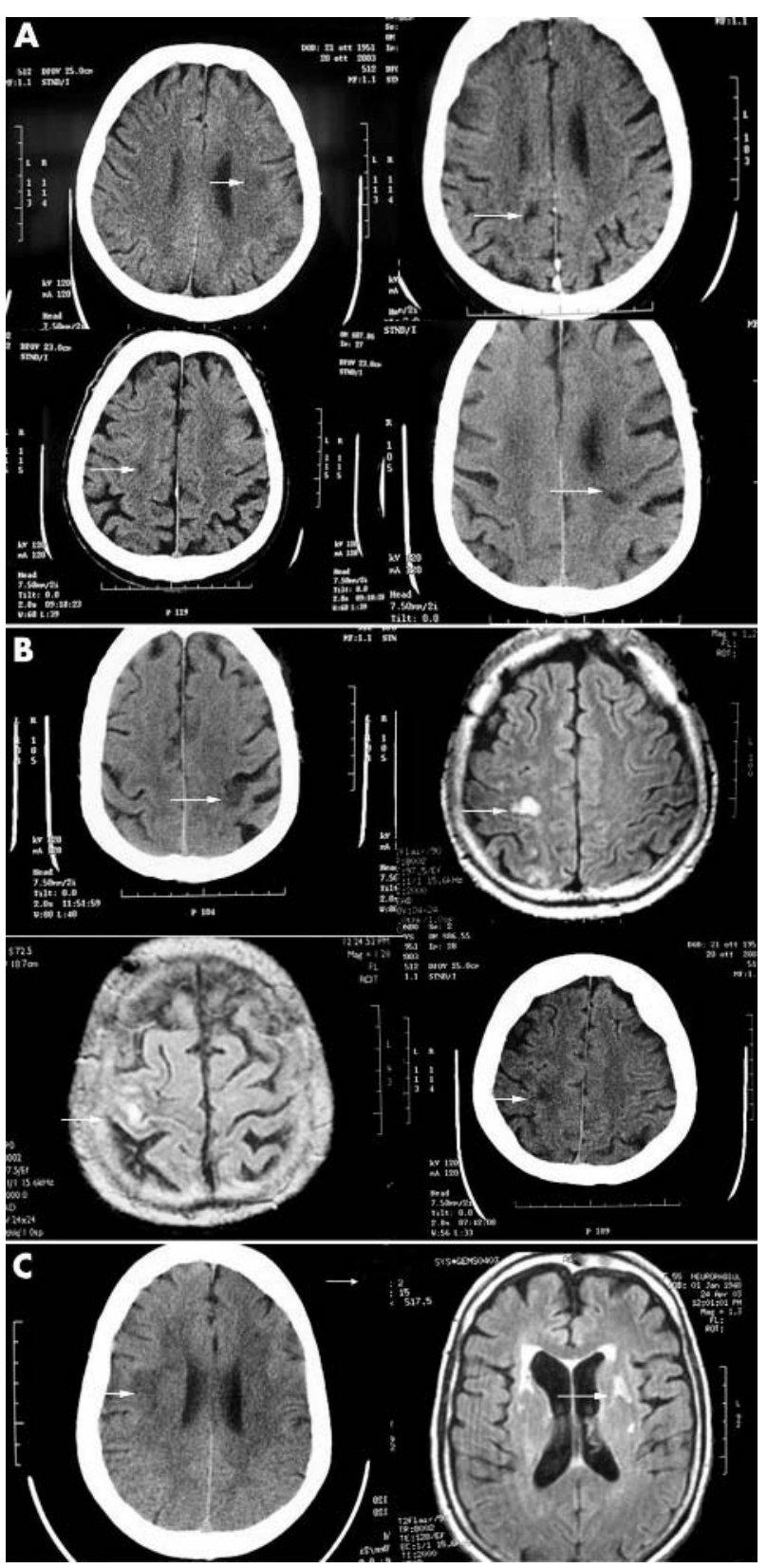

Figure 1 Ischaemic strokes. (A) Subcortical lacunes in patients with monoparesis. (B) Primary motor cortex involvement in patients with monoparesis. (C) Subcortical small infarcts along the corticospinal tract in patients with monoparesis.

\section{DISCUSSION}

Twenty four per cent of patients with stroke and monoparesis had small cerebral haemorrhages. There have been a few reports on monoparesis associated with cerebral haemorrhage $^{9}$ but no prospective studies have been done. Ischaemic or haemorrhagic lesion location was subcortical or in the territory of the posterior circulation in 32 of our 51 patients $(62.7 \%)$. The cause of the symptoms was supratentorial lacunes in $17.6 \%$; subtentorial lacunes localised in the pons were present in $3.9 \%$. The relatively high incidence of small lesions in our series could reflect the recent advances in neuroimaging. In our study, no patient had negative neuroimaging.

Any lesions suitably placed along the course of the corticospinal tract can provoke monoparesis. In our study, only 16 patients with monoparesis $(31.4 \%)$ had a cortical lesion, though previous reports have suggested that the lesions most likely to produce a monoparesis are those in the cortical or the near-cortical area, because somatotopic motor representation is most widely separated at this level. ${ }^{10-12}$

Boundary zones were affected in three patients (parietal lobe) suggesting a haemodynamic infarct. Parietal lobe lesions are known to be associated with motor disorders in animal models as well as in humans..$^{13}{ }^{14}$ The major role of some parietal cortical regions is thought to be connected with motor organisation and in particular with perceptuomotor coordination. ${ }^{15}$ Timsit et al ${ }^{16}$ described an evolving nonpyramidal motor deficit of the hand related to an inferior parietal lobe lesion.

The majority of our patients had brachial monoparesis, while crural monoparesis was present in 33\%. Monoparesis has been found in the lower limbs of patients with contralateral small lesions in the top of the precentral gyrus cortex, but also in patients with small lesions along the corticospinal tract (corona radiata, internal capsule, and pons). ${ }^{17}{ }^{18}$ Lacunes located more posteriorly in the capsule seem likely to produce a greater deficit in the leg than in the arm, but several varieties are encountered, including some where the arm is more affected than the leg. Neuroimaging correlations with the syndrome of paresis have provided only slight support for the classical view of a homunculus in the internal capsule, with the face, arm, and leg displayed in an antero-posterior distribution. Also, lacunes in the white matter which run along the corticospinal tract just under the precentral gyrus could have caused pure monoparesis

Two of our patients had monoparesis caused by pontine infarcts. Pontine motor deficit is present because of involvement of the antero-medial portion and it is more often found in the distal upper limb than in the lower limb, because arm and finger fibres are in the ventro-tegmental junction, whereas leg fibres have a more ventral localisation. ${ }^{19}$

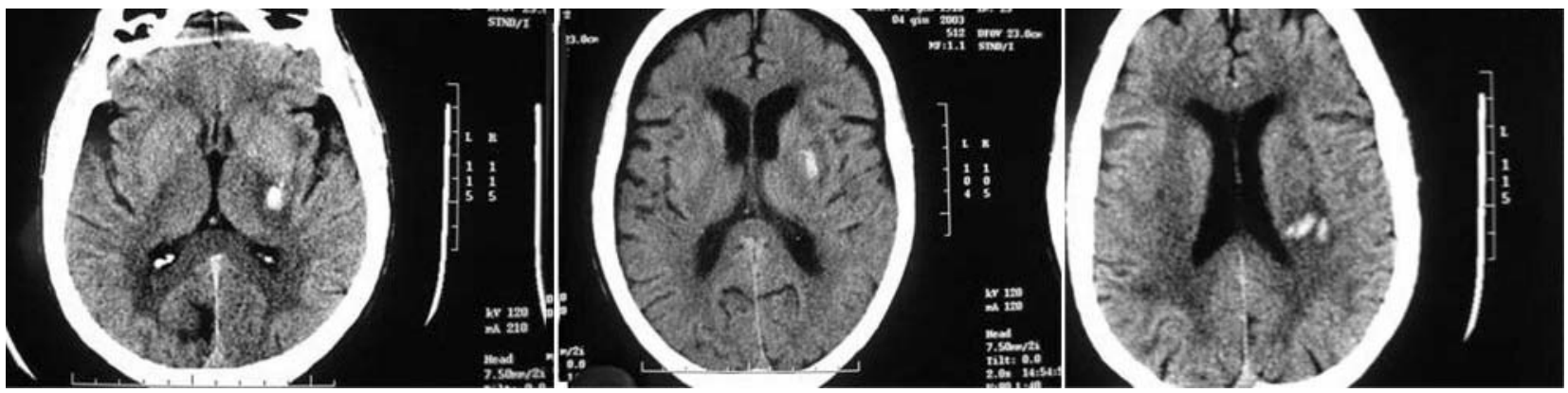

Figure 2 Small subcortical haemorrhages in patients with monoparesis. 
Table 1 Characteristics of the patients and the clinical features

\begin{tabular}{llll}
\hline Risk factor & Total $(\mathbf{n}=51)$ & $\begin{array}{l}\text { Ischaemic stroke } \\
(\mathbf{n}=\mathbf{3 9 )}\end{array}$ & $\begin{array}{l}\text { Haemorrhagic stroke } \\
\text { (n= 12) }\end{array}$ \\
\hline Mean age (years) (mean (SD)) & $71.5(12.5)$ & $71.5(8.7)$ & $71.4(21.1)$ \\
Male sex & $26(51.0 \%)$ & $22(56.4 \%)$ & $4(33.3 \%)$ \\
Hypertension & $35(68.6 \%)$ & $26(66.7 \%)$ & $9(75.0 \%)$ \\
Diabetes mellitus & $14(27.5 \%)$ & $12(30.8 \%)$ & $2(16.7 \%)$ \\
Dyslipidaemia & $14(27.5 \%)$ & $11(28.2 \%)$ & $3(25.0 \%)$ \\
Smoking & $10(19.6 \%)$ & $7(17.9 \%)$ & $3(25.0 \%)$ \\
Alcohol & $9(17.6 \%)$ & $7(17.9 \%)$ & $2(16.7 \%)$ \\
Ischaemic heart disease & $9(17.6 \%)$ & $8(20.5 \%)$ & $1(8.3 \%)$ \\
Previous TIA & $7(13.7 \%)$ & $7(17.9 \%)$ & - \\
Obesity & $6(11.8 \%)$ & $5(12.8 \%)$ & $1(8.3 \%)$ \\
Right side & $27(52.9 \%)$ & $22(56.4 \%)$ & $5(41.7 \%)$ \\
Leg & $17(33.3 \%)$ & $13(33.3 \%)$ & $4(33.3 \%)$ \\
Mostly distal & $4(7.8 \%)$ & $3(7.7 \%)$ & $1(8.3 \%)$ \\
Arm & $34(66.7 \%)$ & $26(66.7 \%)$ & $8(66.6 \%)$ \\
Mostly distal & $8(15.7 \%)$ & $6(15.4 \%)$ & $2(16.7 \%)$ \\
Dizziness & $4(7.8 \%)$ & $3(7.7 \%)$ & $1(8.3 \%)$ \\
Dysarthria & $9(17.6 \%)$ & $7(17.9 \%)$ & $2(16.7 \%)$ \\
\hline TIA, transient ischaemic attack. & & & \\
\hline
\end{tabular}

Table 2 Lesion location

\begin{tabular}{|c|c|c|c|c|c|}
\hline Territory & Total $(n=51)$ & $\begin{array}{l}\text { Ischaemic stroke } \\
(n=39)\end{array}$ & $\begin{array}{l}\text { Haemorrhagic stroke } \\
(\mathrm{n}=12)\end{array}$ & $\begin{array}{l}\text { Upper limb } \\
(n=34)\end{array}$ & $\begin{array}{l}\text { Lower limb } \\
(n=17)\end{array}$ \\
\hline Cortical branches of anterior superficial MCA & $10(19.6 \%)$ & $8(20.5 \%)$ & $2(16.7 \%)$ & $9(26.5 \%)$ & $1(5.9 \%)$ \\
\hline Cortical branches of posterior superficial MCA & $2(3.9 \%)$ & $2(5.1 \%)$ & - & $2(5.9 \%)$ & - \\
\hline Cortical branches of ACA & $4(7.8 \%)$ & $3(7.7 \%)$ & $1(8.3 \%)$ & - & $4(23.5 \%)$ \\
\hline Deep perforators $A C M(<1.5 \mathrm{~cm})$ & $9(17.6 \%)$ & $9(23.1 \%)$ & - & $8(23.5 \%)$ & $1(5.9 \%)$ \\
\hline \multicolumn{6}{|l|}{ Subcortical (corona radiata, centrum semiovale } \\
\hline$>1.5 \mathrm{~cm})$ & $13(25.6 \%)$ & $10(25.6 \%)$ & $3(25.0 \%)$ & $12(35.3 \%)$ & $1(5.9 \%)^{*}$ \\
\hline Watershed infarct (MCA/PCA or MCA/ACA) & $3(5.9 \%)$ & $3(7.7 \%)$ & - & - & $3(17.6 \%)^{*}$ \\
\hline Striato-capsular & $2(3.9 \%)$ & $1(2.6 \%)$ & $1(8.3 \%)$ & - & $2(11.8 \%)$ \\
\hline Thalamic-capsular & $6(11.8 \%)$ & $1(2.6 \%)$ & $5(41.7 \%)^{*}$ & $3(8.8 \%)$ & $3(17.6 \%)$ \\
\hline Brain stem (pons) & $2(3.9 \%)$ & $2(5.1 \%)$ & - & - & $2(11.8 \%)$ \\
\hline
\end{tabular}

A limitation of this study is that it was hospital based and the proportion of patients who had a limb deficit was probably smaller than in the general population because patients with very slight motor deficits are less likely to be admitted to hospital.

In conclusion, isolated monoparesis is a rare symptom in patients with stroke. In our series it was caused by small artery disease in about $40 \%$ of cases and by small cerebral haemorrhages in about $25 \%$. Thus the assumption that a lacunar aetiology or small haemorrhages are not likely causes of isolated monoparesis should be re-examined.

\section{Authors' affiliations}

M Paciaroni, V Caso, P Milia, M Venti, G Silvestrelli, F Palmerini, K Nardi, S Micheli, G Agnelli, Stroke Unit, Department of Neuroscience, University of Perugia, Perugia, Italy

Competing interests: none declared

\section{REFERENCES}

1 Melo TP, Bogousslavsky J, Van Melle G, et al. Pure motor stroke: a reappraisal. Neurology 1992;42:789-98.

2 Castaldo J, Rodgers J, Rae-Grant A, et al. Diagnosis and neuroimaging of acute stroke producing distal arm monoparesis. J Stroke Cerebrovasc Dis 2003; 12:253-8.

3 Fisher CM. Lacunar strokes and infarcts: a review. Neurology 1982;32:871-6.
4 Arboix A, Marti-Vilalta JL, Garcia JH. Clinical study of 227 patients with lacunar infarcts. Stroke 1990:21:842-7.

5 Tei H. Monoparesis of the right hand following a localized infarct in the left "precentral knob". Neuroradiology 1999;41:269-70.

6 Tatu L, Moulin T, Bogousslavsky J, et al. Arterial territories of human brain: brainstem and cerebellum. Neurology 1996;47:1125-35.

7 Tatu L, Moulin T, Bogousslavsky J, et al. Arterial territories of human brain: cerebral hemispheres. Neurology 1998;50:1699-708.

8 Adams HP, Bendixen BH, Kappelle $\sqcup$, et al. Classification of subtype of acute ischemic stroke: definitions for use in a multicenter clinical trial. Stroke 1993;24:35-41.

9 Yoneda Y, Mori E, Tabuchi M, et al. Pure motor monoparesis due to intracranial hemorrhage. Stroke 1993;24:142-3.

10 Yousry TA, Schmid UD, Alkadhi $H$, et al. Localization of the motor hand area to a knob on the precentral gyrus. Brain 1997;120:141-57.

11 Kim JS. Predominant involvement of a particular group of fingers due to small, cortical infarction. Neurology 2001;56:1677-82.

12 Takahashi N, Kawamura M, Araki S. Isolate hand palsy due to cortical infarction: localization of the motor hand area. Neurology 2002;58:1412-14.

13 Sakata H, Taira M. Parietal control of hand action. Curr Opin Neurobiol 1994;4:847-56.

14 Mountcastle VB. The parietal system and some higher brain functions. Cereb Cortex 1995;5:377-90.

15 Critchley M. The parietal lobe. New York: Hafner, 1953.

16 Timsit S, Logak M, Manai R, et al. Evolving isolated hand palsy: a parietal lobe syndrome associated with carotid artery disease. Brain 1997; 120:2251-7.

17 Schneider R, Gautier JC. Leg weakness due to stroke. Site of lesions, weakness pattern and causes. Brain 1994;117:347-54.

18 Kohno Y, Ohkoshi N, Shoji S. Pure motor monoparesis of a lower limb due to a small infarction in the contralateral motor cortex. Clin Imaging 1999;23: 149-51.

19 Kataoka S, Hori A, Shirakawa T, et al. Paramedian pontine infarction. Stroke 1997:28:809-15. 